\title{
WEB PUBLICIDADE: REFLEXÕES À LUZ DA ECOLOGIA MIDIÁTICA
}

\author{
WEB ADVERTISING: REFLECTIONS IN THE LIGHT \\ OF MEDIA \\ PUBLICIDAD EM LA WEB: REFLEXIONES A LA LUZ DE
LA ECOLOGIA DE LOS MEDIOS
}

Taís Steffenello Ghisleni

Doutoranda no Programa de

Pós-Graduação em Comunicação da UFSM.

E-mail: taisghisleni@yahoo.com.br

Eugenia Mariano da Rocha Barichello

Professora do Programa de Pós-Graduação em Comunicação UFSM.

E-mail: eugeniabarichello@gmail.com

\begin{abstract}
Resumo
Contemporaneamente tem ocorrido uma migração da publicidade organizacional para os suportes online. Este texto objetiva refletir sobre o cenário da publicidade e propaganda na atual ecologia midiática e comentar a evolução da publicidade na web desde o advento da internet no Brasil. O artigo possui caráter teórico-reflexivo e orienta-se, fundamentalmente, pela literatura especializada sobre a ecologia dos meios de comunicação e a teoria da midiatização, contribuindo para a compreensão de práticas publicitárias na sociedade midiatizada.
\end{abstract}

Palavras-chave: Ecologia midiática. Estratégias Comunicacionais. Publicidade digital.

\begin{abstract}
Contemporaneously there has been a migration of organizational advertising to online media. This paper aims to reflect on the scenario of advertising and marketing in today's media ecology and comment on the evolution of web advertising since the advent of the Internet in Brazil. The article has theoretical-reflective nature and is oriented primarily in the specialized literature on the ecology of the media and the theory of mediatization, contributing to the understanding of advertising practices in mediatized society.
\end{abstract}

Key words: Media ecology. Communicative strategies. Online advertising.

\section{Resumen}

Hoy en día se ha producido una migración de la publicidad institucional a los medios de comunicación en línea. Este trabajo tiene como objetivo reflexionar sobre el escenario de la 
publicidad y el marketing en el actual escenario y hacer comentarios sobre la evolución de la publicidad en la web desde el advenimiento de la Internet en Brasil. El artículo tiene carácter teórico-reflexivo y está orientado principalmente en la literatura especializada sobre la ecología de los medios de comunicación y la teoría de la mediatización, lo que contribuye a la comprensión de las prácticas de publicidad en la sociedad mediada.

Palabras clave: Ecología de los medios. Estrategias comunicativas. La publicidad en línea.

\section{INTRODUCAO}

Estudos contemporâneos apontam para uma migração da publicidade organizacional que, dos suportes tradicionais, passou a invadir a plataforma on-line, criando mais uma forma de comunicação, e a estabeleceu, estrategicamente, como uma lógica institucional avançada e desterritorializada.

A partir desse pressuposto, podemos dizer que o aporte de experiências trazido pelas tecnologias da internet implica considerar uma combinação de (res)significações a respeito das interações e sociabilidades no contemporâneo. E "compreender essas (trans)formações e seus impactos nos relacionamentos sociais é uma das mais complexas e desafiantes propostas para os pesquisadores de várias áreas do saber" (LEITE; BATISTA, 2012, p. 222).

Este artigo é de caráter teórico-reflexivo e orienta-se, fundamentalmente, pela literatura especializada sobre a ecologia dos meios de comunicação e a teoria da midiatização, estabelecendo as semelhanças entre ambas, na perspectiva de contribuir com o processo de construção do conhecimento das formatações da publicidade na mídia digital.

Entendendo a publicidade como "uma forma de comunicação que utiliza um conjunto de meios pagos, e que influi no público e persuade para a compra de mercadorias ou serviços" (GOMES, 2003, p. 102), este texto objetiva refletir sobre o cenário da publicidade e propaganda na internet, na atual ecologia midiática. A intenção, sobretudo, é comentar a evolução da publicidade na web desde o advento da internet comercial no Brasil.

A tecnologia propicia novas formas de comunicação e de interações socioculturais. " $\mathrm{O}$ ponto de vista não é mais único nem subjetivo, já que se difrata objetivamente por todo o espaço social, dando ao próprio mundo o poder de ver instantaneamente, simultaneamente e globalmente" (SODRÉ, 2002, p. 73). A partir das atualizações de dispositivos midiáticos, como os computadores pessoais e os celulares, novas formas de comunicação se originaram, alterando as relações e interações entre os indivíduos. Para Chinem (2010, p. 70), a necessidade de comunicação das organizações é global, e "no momento que a empresa passa a existir, tem de dizer que existe para poder atingir seu consumidor". Constata-se que uma das 
formas atuais muito utilizadas para este tipo de interação é a inserção das organizações na web.

A pertinência e as oportunidades, proporcionadas pelo uso contínuo da comunicação on-line, são fatores que tornam indispensáveis o constante aprimoramento e investimento por parte das organizações, especialmente porque as transformações tecnológicas e os avanços do campo da comunicação processaram grandes mudanças de alguns anos pra cá. São alterações que afetam também a publicidade e o que se espera dela, que seja um reflexo da realidade e do contexto em que está inserida, seja econômico, social, político ou cultural.

O texto está estruturado em três tópicos principais. O primeiro aborda a comunicação nas organizações dentro do contexto de convergência. Em seguida, conceitua midiatização e ecologia da mídia. E, finalmente, a terceira parte traz um comentário sobre a transição da publicidade tradicional até à webpublicidade.

\section{COMUNICAÇÃO ORGANIZACIONAL EM TEMPOS DE CONVERGÊNCIA}

O sociólogo Manuel Castells, em 1999, já visualizava o futuro da internet como meio de comunicação e ponderava que esta seria uma plataforma sobre a qual a nova sociedade estaria embasada. Para o autor, a sociedade voltada ao uso da informação, a partir de uma revolução tecnológica, trouxe a ideia de que as novas tecnologias da informação estão integrando o mundo em redes interligadas globalmente. Assim, "a informação representa o principal ingrediente de nossa organização social, e os fluxos de mensagens e imagens entre as redes constituem o encadeamento básico de nossa estrutura social" (Castells, 1999, p. 573).

Castells (2012) também afirma que a relação equilibrada entre tecnologia e organizações se trata de uma via de mão dupla: ao mesmo tempo em que as tecnologias alteram o modo de vida dos homens e o modo como os homens as vivenciam, também as moldam. Podemos compreender, com base nessa afirmação, que as tecnologias da informação e comunicação condicionam uma nova realidade da comunicação nas organizações.

Curvello (2012, p. 137) explica que "a tecnologia desenha uma nova forma de conversar e dialogar e a própria organização tem de repensar e reformular seus discursos legitimadores". Portanto, as tecnologias digitais da informação e comunicação são consideradas dispositivos $^{\mathrm{i}}$ que permitem novas possibilidades de interação das organizações com seus públicos e estas relações de interatividade são estabelecidas via estratégias de comunicação pelo sistema da internet ${ }^{\mathrm{ii}}$.

A ascensão da internet para os mais diversificados públicos e o crescimento de novas tecnologias, que servem como suporte para a comunicação, ampliam a expansão da cultura de 
convergência. De acordo com Jenkins (2009, p. 29), “convergência é uma palavra que consegue definir transformações tecnológicas, mercadológicas, culturais e sociais". Ela envolve três conceitos básicos: convergência dos meios de comunicação, cultura participativa e inteligência coletiva. Por convergência, Jenkins (2009) se refere ao fluxo de conteúdos através de múltiplas plataformas de mídia, à cooperação entre múltiplos mercados midiáticos e ao comportamento migratório dos públicos dos meios de comunicação, que vão a quase qualquer parte em busca das experiências de entretenimento que desejam. Entretanto, apesar de ocorrer na mente dos consumidores, a convergência hoje possui inúmeros dispositivos midiáticos para se desmembrar, como as inúmeras redes sociais, especialmente feitas para falar sobre marcas e produtos, redes que possibilitam a inserção inclusive de vídeos e fóruns.

As informações disseminadas pela rede podem interferir nas opções de escolha dos usuários. Por este motivo, o site tornou-se uma ferramenta essencial para divulgação e relacionamento das empresas com o seu público-alvo. A convergência e a interatividade permitirão novas formas de relacionamentos e entretenimento e, ainda possibilitar que os conteúdos passem a ser formulados de forma colaborativa, fazendo do usuário um produtor, e não apenas um receptor das mensagens.

Neste contexto, por um baixo custo, as empresas podem e precisam estar presentes na web, utilizando as redes sociais como ferramentas para conectar pessoas com interesses ou características comuns, formando as redes de relacionamento.

Gómez (2009, p. 84) lembra que "a chegada de um novo meio ou tecnologia não supõe necessariamente, nem tampouco imediatamente a suplantação do anterior". O autor cita várias razões e explica, especialmente, que esta transformação envolve outros fatores, além dos estritamente técnicos ou instrumentais. Evidencia que cada nova tecnologia necessita de um tempo de aprendizagem e apropriação por parte dos usuários, e também que cada nova tecnologia atende uma ou mais necessidades anteriores, mas não todas, o que causa um reordenamento na sociedade.

Segundo Lewis e Bridges (2004, p. 114) "na era da informação um número cada vez menor de bens e serviços está sendo criado exclusivamente por consumidores ou produtores, mas pela parceria inteligente de ambos". Pelo meio da interação na internet, onde o internauta deixa de ser passivo e se torna ativo no recebimento de mensagens, podendo interagir com outros internautas e até mesmo com a marca, a cultura da convergência se tornou mais presente e interativa. 


\section{A TEORIA DA MIDIATIZAÇÃO E A PERSPECTIVA ECOLÓGICA}

Por midiatização da sociedade, entendemos o "processo pelo qual a sociedade, em um grau cada vez maior, está submetida a ou torna-se dependente da mídia e de sua lógica" (HJARVARD, 2012, p. 64). O autor explica que existem semelhanças entre a ecologia dos meios de comunicação e a teoria da midiatização, já que ambas

[...] optam por observar o impacto dos meios de comunicação em uma perspectiva global e centram-se em outros aspectos que não somente o conteúdo e a utilização destes - enfoques que, por sua vez, têm ocupado grande parte da pesquisa sobre a comunicação de massa (HJARVARD, 2012, p. 60).

Hjarvard (2012) acrescenta, ainda, que a teoria da midiatização e a ecologia dos meios se equivalem quando abordam os meios de comunicação e seus impactos, especialmente sobre as relações interpessoais a que dão origem.

A Teoria do Meio, de uma forma geral, não desconsidera a importância do conteúdo das mensagens, mas centra o foco de atenção sobre o canal porque ele pode trazer conseqüências muito mais significantes. Portanto, ela centra sua preocupação nas características específicas de cada meio de comunicação (SOUZA, 2003, p. 5).

Salienta-se que esta questão é tensionada ainda pela cultura da convergência, pois, com esta os indivíduos têm um cenário mais amplo para participar de discussões sobre produtos e marcas que consomem, compartilhando informação entre um público que possui os mesmos hábitos de consumo. Este público é aconselhado a julgar favoravelmente um produto/serviço ou uma marca pelo texto publicitário, dominantemente deliberativo ${ }^{\mathrm{iii}}$, e isto pode resultar em uma ação posterior de compra (CARRASCOZA, 1999).

Destaca-se, ainda, que o ambiente composto por redes e comunidades virtuais proporciona a possibilidade de incentivar o público a participar pertinentemente na construção de marcas e produtos, com opiniões a respeito dos seus interesses e desejos como consumidores. Portanto, é uma forma vantajosa de pesquisar as principais tendências de um público específico e intensificar a relação entre consumidor e marca.

Hjarvard (2012, p. 60) lembra que a teoria da midiatização é semelhante à ecologia dos meios de comunicação ${ }^{\text {iv }}$ "no que diz respeito à observação das diferentes formatações de cada meio de comunicação e dos impactos sobre as relações interpessoais às quais dá origem". Neste sentido, Scolari (2012, p. 1) explica que a "chegada de novas espécies de mídia está transformando o ecossistema, forçando as espécies que habitam a sua adaptação 
para sobreviver". Portanto, é tempo de ir além da mera descrição e começar a desenvolver ferramentas teóricas e metodológicas para o estudo aprofundado da ecologia de mídia ${ }^{\mathrm{v}}$. O autor informa ainda que a diferença entre antigos e novos meios de comunicação não é um fato teoricamente importante, já que os "novos" meios de comunicação de hoje, serão os "velhos" de amanhã.

De acordo com McLuhan (1964), os efeitos da tecnologia vão além dos níveis de opinião e atitudes para modificar as relações entre os sentidos e as estruturas de percepção. Para os teóricos do meio esse é o motivo pelo qual o estudo do canal é tão importante e, nesse caso, até mais que o estudo das mensagens. $\mathrm{O}$ meio media as relações entre os homens e entre o homem e o meio-ambiente sem ser percebido, mas transformando toda a predisposição original de se comunicar e perceber o mundo (SOUZA, 2003, p. 6).

Vale lembrar que o termo "ecologia da mídia", foi definido por Neil Postman em 1970 como "o estudo das mídias como ambientes". O autor explica ${ }^{\mathrm{vi}}$ que este conceito investiga como os meios de comunicação afetam a percepção, a compreensão, os sentimentos e os valores humanos. E o estudo dos ambientes inclui tanto a estrutura e conteúdo quanto o impacto sobre as pessoas por ser um sistema de mensagens complexo que impõe aos seres certas maneiras de pensar, sentir e se comportar.

"Os meios de comunicação não são apenas tecnologias que as organizações, os partidos ou os indivíduos podem optar por utilizar - ou não utilizar - como bem entenderem" (HJARVARD, 2012, p. 54). O contexto exposto rompe com as práticas comunicacionais das instituições nas últimas décadas e faz com que as organizações batalhem para não ficar de fora destas novidades. Até porque precisam se adaptar ao mercado para sobreviver, já que, como bem pontua Scolari (2012, p. 1), a “chegada de novas espécies de mídia está transformando o ecossistema".

Considera-se que só utilizando ações de comunicação e temas consistentes, as organizações terão condições de estabelecer sua reputação por meio de uma presença significativa e diferenciada no mercado, a fim de atrair e reter o público-alvo. Pode-se dizer que esta comunicação diferenciada passa pela presença digital ${ }^{\text {vii }}$ das organizações na internet, que é determinada pelos pontos de contato do público com a marca e/ou empresa que ela representa (GABRIEL, 2010).

E para ampliar o contato do público com as marcas evidencia-se a importância da publicidade e propaganda que teve o seu auge com as mídias de massa, mas que, com a proliferação de produtos, marcas e mídias durante as últimas décadas, passou a dispersar a atenção do público, pecando pelo excesso. No entanto, Gabriel (2010, p. 18) lembra que "a 
propaganda continua tendo o seu espaço e encontrou formas de utilizar as novas mídias digitais com bastante sucesso. Exemplos disso são os links patrocinados e banners presentes em diversas plataformas digitais". A autora complementa ainda que, se "usada de forma apropriada, alinhada com a relevância e diminuindo a dispersão, a propaganda ${ }^{\text {viii }}$ continua sendo um instrumento estratégico de comunicação" (GABRIEL, 2010, p. 18).

A publicidade é, na verdade, um sistema que organiza a sua produção de acordo com as práticas cotidianas do contexto em que está inserida e, que, de certa forma, acaba agindo como um campo de identificações no espaço midiatizado. Por este motivo, lembramos que não é possível analisá-la somente no seu contexto mercadológico, já que a publicidade também transmite valores e sentidos e se organiza com total relação com a ambiência social que é a midiatização.

Entende-se que o papel da publicidade é o de tentar captar a atenção, despertar o desejo e criar a necessidade de uso de um produto, ou serviço, em possíveis consumidores, clientes, mercado e opinião pública em geral. E que sempre que a humanidade evolui, são modificados os hábitos e comportamentos do homem, e com a publicidade não é diferente. Com o surgimento da internet, e a criação do marketing voltado para a rede mundial, a publicidade também precisa se adaptar e renovar seus meios de expressão e de comunicação.

\section{DA PUBLICIDADE TRADICIONAL À WEBPUBLICIDADE}

"Publicidade é uma comunicação impessoal de informações por diversos meios, geralmente de natureza persuasiva, sobre produtos (bens e serviços) ou ideias, e geralmente é paga por um patrocinador identificado" (STRAUSS; FROST, 2012, p. 203).

Piedras (2005) comenta que é necessário pensar a publicidade a partir de uma perspectiva que nos leve a considerar as ambiguidades e as contradições do seu processo comunicativo, superando a fragmentação das análises isoladas de anúncios e campanhas, de que tem se ocupado a maioria das pesquisas analisadas.

Como objeto de estudo, ela pode ser observada desde diferentes perspectivas, as quais configuram o seu entendimento. Se, de um lado, a publicidade pode ser reduzida a uma mensagem com a função de produzir e divulgar informações para vender bens, de outro, ela pode ser entendida como um processo comunicativo, cujas mensagens persuasivas são produzidas e recebidas em contextos contraditórios, implicados tanto pelo sistema hegemônico da estrutura econômica, quanto pelas práticas culturais dos sujeitos. Entre essas duas perspectivas, vemos transcorrer a evolução das abordagens da publicidade, como um reflexo das diferentes teorias utilizadas para pesquisar a comunicação (PIEDRAS; JACKS, 2006, p. 3). 
Nesta linha de pensamento, Trindade e Filho (2006, p. 5) comentam que a

[...] comunicação midiática publicitária, [...] tem uma responsabilidade social muito grande na formação do repertório cultural do indivíduo e que sua presença cotidiana e os seus respectivos processos de produção, bem como o consumo de seus produtos, geram [...] a sociedade midiatizada.

Estes autores entendem que "o papel midiatizador dos meios de comunicação, com suas linguagens como a publicidade, são constitutivos das conjunturas socioculturais contemporâneas" (TRINDADE; FILHO, 2006, p. 5).

Pensando nestas considerações, seja no formato on-line ou tradicional, por representar a sociedade em que está inserida, é vital para a publicidade "trabalhar com os valores e elementos constitutivos do sistema, sem os quais ela não realiza sua interação social" (JACKS, 2003, p. 124).

Segundo Curvello (2012, p.144) a visão de McLuhan se confirmou em muitos aspectos e que suas ideias e provocações ainda serão muito úteis para ajudar a iluminar os caminhos daqueles pesquisadores que se aventurarem a percorrer o futuro que desde já, e sempre, está em construção.

Rodrigues e Toaldo (2013) propõem o estudo da publicidade em cinco fases: 1) fase artesanal; 2) fase agenciaria; 3) publicidade empresarial; 4) publicidade mercadológica; e 5) publicidade associativa. Os autores observam que a "trajetória da publicidade permite apresentar, além das práticas profissionais em diferentes contextos, os ambientes econômicos, políticos e sociais, que auxiliam a entender as mudanças de paradigmas e a perspectivar o surgimento de novas condutas" (p. 12).

E, avançando nesta classificação, também podemos pensar na publicidade na web, já que,

Todo o espaço pago em um website ou em um e-mail é considerado publicidade. A publicidade na internet se assemelha à publicidade na mídia tradicional, na qual as empresas criam conteúdo, atraem um público e, em seguida, vendem espaço para seus anunciantes. Isso pode ser confuso, principalmente quando um banner publicitário, que promove um dos produtos da empresa, aparece no próprio website da empresa. O fator determinante é a troca - se a empresa paga com dinheiro ou permuta com bens um espaço para colocar o conteúdo que ela cria, o conteúdo é considerado publicidade (STRAUSS; FROST, 2012, p. 204).

A publicidade sofreu mudanças ao longo do tempo e as organizações precisam se estruturar para ter capacidade de produzir conteúdos mais complexos e utilizar 
adequadamente as possibilidades, mas para isto é preciso criar conexões entre o espaço virtual e a vida real do consumidor.

Os hábitos e comportamentos do homem são modificados com a evolução da humanidade, e na publicidade ocorre o mesmo. Com o surgimento da internet, e a criação de ações voltadas para a rede mundial, a publicidade passou a renovar seus meios de expressão, comunicação. Juntamente com isto, a internet também passou por transformações para receber as ações pensadas especificamente para esta plataforma e trouxe novas lógicas aos regimes de visibilidade pública.

Barichello (2001) explica que antes da existência da mídia a visibilidade pública se dava no local dos acontecimentos, mas com o desenvolvimento dos meios de comunicação foram destacadas novas formas de visibilidade, configurando a mídia como um espaço de mediação em que as lutas por reconhecimento se tornam lutas pela visibilidade. Atualmente, é possível sinalizar que a internet possui uma função legitimadora para as organizações e para os públicos que fazem parte dela. Sendo assim, configura-se em um dispositivo de visibilidade e, também, de legitimação, partindo do pressuposto de que atualmente não é suficiente dar visibilidade às ações, mas torná-las legítimas por meio de suportes de visibilidade (BARICHELLO, 2001).

Os espaços de visibilidade, gerados pela internet para as organizações, estão ampliando suas potencialidades desde o inicio da publicidade comercial, em 1995, pois neste período já existiam sites voltados à publicidade e divulgação da marca/produto das empresas. Alguns sites apresentavam apenas blocos de textos e uma programação simples; já outros inovavam em colocar mais imagens e dividir o conteúdo em páginas. A publicidade começou a se fazer presente por meio de banners comuns, cujas imagens com informações divulgavam o produto ou a marca que anunciava, mas com o tempo, este tipo de anúncio foi se tornando obsoleto, pois os usuários passaram a ignorar seu conteúdo.

Conforme a revisão bibliográfica realizada para a construção desta reflexão, pode-se dizer que, no início da internet comercial, a forma mais comum de se anunciar na web era por meio de banners de imagens estáticas ou gifs ${ }^{i x}$ animados. Hoje, os banners ainda aparecem no layout das páginas, porém de uma forma mais atraente.

Sabe-se que o objetivo da publicidade on-line, como de toda a publicidade, é o de disseminar informações com o intuito de influenciar a transação entre comprador e vendedor. Porém, segundo Zeff e Aronson (2000), a web tem a vantagem de permitir a interação do consumidor com a peça publicitária, o que nem sempre acontece com outras mídias. Esta interação é possível já que, com um clique, o consumidor pode ter acesso a informações 
detalhadas do produto de seu interesse, comparar preços e efetuar sua compra, tudo no ambiente da internet.

O surgimento da web $2.0^{\mathrm{x}}$ possibilitou uma interação maior entre o internauta e a rede, e levou à criação de anúncios interativos e inovadores, capazes de atrair o olhar do usuário da rede. Estes anúncios são usados graças à tecnologia que dia após dia é ampliada, e às crescentes melhorias no acesso à internet. Pode-se dizer que, são estes fatores que permitem que inovações publicitárias possam ser criadas e melhoradas a cada dia.

Strauss e Frost (2012) relatam que a web 2.0 contextualizou novos desafios e oportunidades para os profissionais de marketing. Entre eles: 1) a transferência do poder dos vendedores para os compradores; 2) o uso do marketing de atração (inbound marketing), ou seja, o produto/serviço é facilmente encontrado no mundo on-line, e com isto deixa de interromper os clientes com ações tradicionais; 3) o engajamento (envolvimento emocional e cognitivo dos clientes); e, ainda, 4) métricas da mídia social. Os autores ainda trazem outros elementos-chave do cenário da web 2.0 como: o amadurecimento da adesão à internet (o uso intenso da web e do e-mail já é uma atividade corriqueira); e também das vendas a varejo online; os mecanismos de busca atualmente são mecanismos de construção de reputação; o conteúdo como um fator soberano; a integração entre estratégias on-line e off-line (marketing multicanal); a possibilidade de velocidade rápida de acesso à internet; o papel do capital intelectual (profissionais com know-how); e a cauda longa, que explica como a computação e o armazenamento de baixo custo viabilizam a venda de pequenas quantidades de um grande número de produtos on-line com grandes receitas.

As práticas de publicidade na plataforma on-line emergem como tema desta reflexão. Marshal (2005, p. 15) comenta que "a comunicação no ciberespaço vem se configurando com base nas especificidades da internet". E, acrescenta, que tais especificidades influenciam a maneira como as pessoas vivenciam, representam e constroem suas experiências e crenças em textos orais e escritos.

A conectividade oferece mais autonomia e independência, o que significa, conforme vem apontando Lemos (2003), trata-se de pensar não na substituição de práticas e modalidades midiáticas, mas na sua conformação sob os múltiplos suportes que a tecnologia disponibiliza. Nesta mesma linha, Sodré (2002, p. 78) já afirmava que "a passagem da comunicação de massa às novas possibilidades técnicas não significa a extinção da mídia tradicional, mas a coexistência e mesmo a integração da esfera do atual [...] com a do ciberespaço". 
Dessa forma, a comunicação se torna cada vez mais complexa e desafiadora para seus gestores.

\begin{abstract}
$\mathrm{O}$ uso da Internet pelas organizações passou a representar a possibilidade de estreitamento de relações com seus diversos públicos. Nos sites as organizações se apresentam, se tornam 'visíveis', se dão a conhecer. Preocupam-se com o seu conteúdo, mas também com a forma como este é apresentado, buscando atender os diferentes perfis de seus usuários. A localização dos links, a posição da logomarca, a utilização de slogan, a seleção das cores, a existência (ou não) de animação, a presença de fotos, propaganda, janelas pop-up, os serviços e as formas de interatividade disponibilizadas assumem relevância nesse meio de comunicação (MOURA; SCROFERNEKER, 2008, p. 27).
\end{abstract}

Atualmente, já existem diversas formas de se fazer publicidade na web que vão desde um simples banner até hotsites completos. Entretanto, ainda percebe-se a necessidade de que sejam realizadas muitas pesquisas e análises de mercado para saber qual o tipo de publicidade é mais indicado para o que se deseja atingir. Isto, por que

[...] o desenvolvimento dos meios de comunicação cria novas formas de ação e de interação e novos tipos de interação sociais - formas que são bastante diferentes das que tinham prevalecido durante a maior parte da história humana. Ele faz surgir uma complexa reorganização de padrões de interação humana através do espaço e do tempo (THOMPSON, 1998, p. 77).

A publicidade on-line possui quatro vantagens distintas, segundo Zeff e Aronson (2000) que incluem: 1) Focalização, ou seja, é possível focar os usuários geograficamente ou psicograficamente, através da hora de acesso ou do site onde a publicidade será inserida; 2) Monitoramento: o marketing pode monitorar a interação de seus clientes atuais e potenciais com sua marca, descobrindo ou ratificando o real interesse deles em relação ao produto/serviço oferecido; 3) Entrega e flexibilidade, já que a internet possibilita que uma campanha esteja disponível o tempo todo, e que possa ser suspensa ou alterada em tempo real. Outra grande vantagem é o baixo custo de desenvolvimento e alteração de uma peça publicitária para o meio on-line; e 4) Interatividade, pois a internet é a única mídia que permite transformar de forma simples o papel do consumidor, do papel de receptor da informação, para agente de busca e compra.

Com isso, o papel da publicidade é ampliado para além de fomentador da decisão de compra, para efetivador de compra e este é um tema que não se esgotará nos próximos anos e será possível adicionar questionamentos e descobrir novas ideias ao longo do caminho. $\mathrm{O}$ certo é que a internet está em constante transformação e a cada dia que passa aumenta o número de pessoas conectadas à web. 
É perceptível que o tempo e a atenção dos consumidores estão se voltando para mídias na internet. Está acontecendo um reequilíbrio do mercado, já que as verbas estão sendo destinadas para onde está o consumidor.

Atualmente, já existem diversas formas de se fazer publicidade na web que vão desde um simples banner até hotsites completos e os formatos da publicidade on-line se alteram em curtos espaços de tempo, acompanhando as transformações das tecnologias e do próprio meio. É preciso muita pesquisa e análise de mercado para saber qual o tipo de publicidade é o mais indicado para o que e quem se deseja atingir, já que a internet é um meio de comunicação que possibilita grande acesso de informação, e é entendida pelos usuários como um ambiente de pesquisa de informação, de encontro e de compartilhamento.

\section{CONSIDERAÇÕES}

A atual ecologia midiática faz parte de um processo que acontece em longo prazo e, no qual, o crescimento e a influência dos meios de comunicação também alteram as organizações e os seus modos de interação.

Com o passar do tempo os hábitos e comportamentos dos indivíduos são modificados, e com a publicidade ocorre o mesmo. Desde o surgimento da internet e a criação de ações de marketing voltadas para a rede mundial, a publicidade também renovou em seus meios de expressão e comunicação.

No ecossistema midiático digital, ocorreram transformações estruturais na publicidade e em suas práticas e, atualmente é possível perceber que a publicidade tradicional está migrando para a internet, conforme aumenta o uso da rede pelos consumidores. Assim, estudos sobre o impacto da publicidade on-line, e a participação da tecnologia, neste contexto, facilitarão a criação de anúncios on-line e também contribuirão para essa tendência.

Embora em um período relativamente pequeno, que inclui menos de 20 anos, se considerarmos o seu início em 1995, o ecossistema publicitário digital já passou por algumas fases que vão desde a inserção dos primeiros banners com conteúdos estáticos, reproduzidos da mídia impressa, até aqueles com formatos em movimento, dinâmicos e interativos.

A publicidade on-line transformou práticas tradicionais da publicidade e abriu espaço para interações mais complexas, oferecendo uma nova dimensão à comunicação organizacional e à pesquisa nesta área. Neste sentido, é importante, e necessário que mais estudos busquem dar conta deste fenômeno em plena processualidade.

\section{REFERÊNCIAS}


BARICHELlO, Eugenia Maria Mariano da Rocha. Apontamentos em torno da visibilidade e da lógica de legitimação das instituições na sociedade midiatizada, In: DUARTE, E. B.; CASTRO, M. L. D. de (Org.). Em torno das mídias: práticas e ambiências. Porto Alegre: Sulina, 2008. p. 236-68.

BARICHELlO, Eugenia Maria Mariano da Rocha. Comunicação e comunidade do saber. Santa Maria: Palotti, 2001.

CARRASCOZA, João Anzanello. A evolução do texto publicitário: a associação de palavras como elemento de sedução na publicidade. São Paulo: Futura, 1999.

CASTELLS, Manuel. A Sociedade em rede. A era da informação: economia, sociedade e cultura. São Paulo: Paz e Terra, 1999. v.1.

- Castells debate os dilemas da internet. (2012). Outras palavras. Recuperado de: $<$ http://www.outraspalavras.net/2012/01/17/castells-debate-os-dilemas-da-internet/> Acesso em: 14 set. 2012.

CHINEM, Rivaldo. Introdução à comunicação empresarial. São Paulo: Saraiva, 2010.

COVALESKI, Rogério. Cinema, publicidade, interfaces. Curitiba: Maxi, 2009.

CURVELLO, J. J. Visão e atualidade das contribuições de McLuhan sobre a automação e os consequentes impactos nas organizações, na comunicação e no mundo do trabalho. (2012). In: SOUZA, J. ; CURVELLO, J.J; RUSSI, P. (org.) 100 anos de McLuhan. Brasília, DF: Casa das Musas. Recuperado de: <http://teoriasetecnologiasda comunicacao. org/wp-content/uploads/ 100anosMcLuhan-ebook.pdf>. Acesso em: 01 mar. 2014.

GABRIEL, Martha. Marketing na era digital: conceitos, plataformas e estratégias. São Paulo: Novatec, 2010.

GÓMEZ, Guillermo Orozco. Comunicação social e mudança tecnológica: um cenário de múltiplos desordenamentos. In: HALLIDAY, Tereza Lúcia. Discurso institucional: uma abordagem retórica. In: KUNSCH, Margarida Maria Krohling. (org). Comunicação organizacional: linguagem, gestão e perspectivas, v. 2. São Paulo: Saraiva, 2009. cap. 2, p.31-52.

GOMES, Neusa Demartini. Publicidade: comunicação persuasiva. Porto Alegre: Sulina, 2003.

HJARVARD, Stig. Midiatização: teorizando a mídia como agente de mudança social e cultural. Traduzido Daniela Pintão. Revista Matrizes, São Paulo, Brasil, ano 5, n. 2, p. 53-91. jan./jun. 2012.

JACKS, Nilda. Mídia nativa: indústria cultural e cultura regional. Porto Alegre: Universidade/UFRGS, 2003.

JENKINS, Henry. Cultura da convergência. São Paulo: Aleph, 2009.

LEMOS, André. Cibercultura: alguns pontos para compreender a nossa época. In LEMOS, André; CUNHA, Paulo (orgs). Olhares sobre a cibercultura. Porto Alegre: Sulina, 2003. p. 11-23.

LEWIS, David; BRIDGES, Darren. A alma do novo consumidor. São Paulo: M. Books, 2004.

LEITE, Francisco Vanildo; BATISTA, Leandro Leonardo. Os grupos de referência na internet e os esforços da publicidade para atingi-los. Comunicação \& Sociedade, 2012.v. 33, p. 221-254 
MARSHAL, Débora. Pesquisadores da linguagem no ciberespaço: um estudo sobre o gênero home page pessoal. Dissertação (Mestrado em Letras) - UFSM. PPGL. Universidade Federal de Santa Maria, Santa Maria, RS, Brasil, 2005.

MOUILLAUD, Maurice; Sérgio Dayrell Porto (org.). O Jornal: da forma ao sentido. Brasília: Paralelo $15,1997$.

MOURA, Claudia P.; SCROFERNEKER, Cleusa M. Novas perspectivas para as Relações Públicas no espaço virtual in: MOREIRA, Elisabeth; PONS, Mônica (orgs.) Perspectivas em Relações Públicas. Santa Cruz do Sul: Edunisc, 2008.

PIEDRAS, Elisa. A articulação da publicidade com o mundo social: a constituição do fluxo publicitário nas práticas de produção e de recepção. Dissertação (Mestrado em Comunicação e Informação) - Universidade Federal do Rio Grande do Sul, Porto Alegre, 2005.

PIEDRAS, Elisa; JACKS, Nilda. A contribuição dos estudos culturais para a abordagem da publicidade: processos de comunicação persuasiva e as noções de articulação e fluxo. E-Compós, 2006. v. 6, p. 1-16.

RODRIGUES, André Iribure; TOALDO, Mariângela Machado. A Perspectiva Histórica da Publicidade Brasileira: uma proposta de estudo. 2013. Trabalho apresentado. IV Pró-Pesq PP Encontro de Pesquisadores em Publicidade e Propaganda. De 23 a 24/05/2013. CRP/ECA/USP, 2013.

SCOLARI, Carlos A. Ecología mediática, evolución e interfaces. Hipermediaciones, abr. 2012. Recuperado de: $\quad<$ http://hipermediaciones.com/2012/04/23/ecologia-mediatica-evolucion-einterfaces/>. Acesso em: 11 out. 2012.

SODRÉ, Muniz. Antropológica do espelho: uma teoria da comunicação linear e em rede. Petrópolis, RS: Vozes, 2002.

SOUZA, Janara Kalline Leal Lopes de. Estudo dos meios de comunicação. A contribuição da teoria do meio. In: XXVI CONGRESSO BRASILEIRO DE CIÊNCIAS DA COMUNICAÇÃO. Anais ..., Belo Horizonte, MG, set. 2003.

STRAUSS, Judy; FROST, Raymond. E-marketing. 6. ed. Trad. Regina Claudia Loverri. São Paulo: Pearson Prentice Hall, 2012.

THOMPSON, John B. A mídia e a modernidade: uma nova teoria social da mídia. Petrópolis, RJ: Vozes, 1998.

TRINDADE, Eneus; FILHO, Valdemar Siqueira. O capital simbólico da publicidade em contextos midiatizados: uma reflexão teórica. In: XI SIMPÓSIO DE CIÊNCIAS DA COMUNICAÇÃO NA REGIÃO SUDESTE, Anais ..., Ribeirão Preto, SP, maio, 2006.

ZEFF, Robbin; ARONSON, Brad. Publicidade na internet. Rio de Janeiro: Campus, 2000.

Original recebido em: 03/02/2014

Aceito para publicação em: 20/07/2014 
Taís Steffenello Ghisleni

Prfessora da Unifra, Doutoranda no Programa de Pós-Graduação em Comunicação da UFSM.

Eugenia Mariano da Rocha Barichello

Professora do Programa de Pós-Graduação em

Comunicação e dos cursos de graduação em

Comunicação da UFSM. Pesquisadora de Produtividade em Pesquisa do CNPq. Doutora em

Comunicação pela UFRJ.

\footnotetext{
${ }^{\mathrm{i}}$ Mouillaud (1997) define o dispositivo como o lugar físico ou abstrato no qual o texto se inscreve, sendo que texto engloba toda e qualquer forma de inscrição, seja linguagem, ícone, som, gesto etc.

ii A internet é entendida neste estudo como um dispositivo, e sendo assim, um espaço no qual se constroem a visibilidade midiática e a legitimação das organizações.

iii Aristóteles apresenta 3 gêneros da retórica: deliberativo (voltado para o futuro, aconselha-se ou não sobre uma questão de interesse particular ou público); judiciário (voltado para o passado, ações de acusação ou defesa) e demonstrativo (tempo presente, que faz elogio ou censura) (CARRASCOZA, 1999).

${ }^{\text {iv }}$ Também conhecida por teoria do meio (HJARVARD, 2012, p. 60).

"No Brasil as pesquisas sobre o "ecossistema midiático digital" ainda são recentes, embora este conceito tenha origem nos anos 1960, com Innis, McLuhan e Postmann.

vi Informação retirada do Media Ecology Association, disponível em: <http://www.media-ecology. org/media_ecology/index.html >. Acesso em: 11 out. 2012.

vii Presença digital "refere-se à existência de algo (seres humano, marcas, empresas, coisas etc.) no ambiente digital" (GABRIEL, 2010, p. 249).

viii Os termos publicidade e propaganda não são sinônimos e, especialmente em inglês são utilizados de forma diferenciada do que na literatura brasileira, aumentando a imprecisão conceitual Sampaio (2003, p. 27 apud COVALESKI, 2009, p. 21-22), por exemplo, utiliza três termos para definir os diferentes aspectos comunicacionais de cada forma de divulgação: "Advertising - anúncio comercial, que visa divulgar e promover o consumo de bens; Publicity - informação disseminada editorialmente, sobre pessoas, produtos, serviços, empresas, entre outros; Propaganda - disseminação de ideias, de cunho político, religioso ou ideológico".

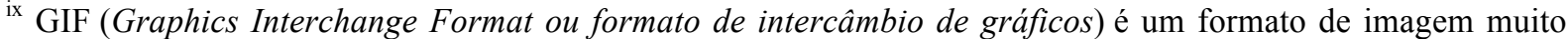
usado na internet [...]. Um tipo particular de GIF bastante conhecido é o chamado GIF animado. Ele na verdade é composto de várias imagens do formato GIF, compactadas em um só arquivo. Essa variante é utilizada para compactar objetos em jogos eletrônicos, para usar como emoticon em mensageiros instantâneos e para enfeitar sites na internet. Disponível em: $\quad$ http://www.techtudo.com.br/ artigos/noticia/2012/04/o-que-egif.html>. Acesso em: 03 set. 2013.

${ }^{x} \mathrm{O}$ termo web 2.0 é utilizado para descrever a segunda geração da World Wide Web - tendência que reforça o conceito de troca de informações e colaboração dos internautas com sites e serviços virtuais. A ideia é que o ambiente on-line se torne mais dinâmico e que os usuários colaborem para a organização de conteúdo. Disponível em: $<$ http://www1.folha.uol.com.br/folha/informatica/ult124u20173.shtml $>$. Acesso em: 15 out. 2012.
} 